\title{
Negotiating big deals ACRL/SPARC Forum at the 2020 ALA Midwinter Meeting
}

\begin{abstract}
A t the ACRL/SPARC Forum at the 2020

ALA Midwinter Meeting in Philadelphia, three panelists discussed efforts to negotiate with vendors regarding "Big Deal" journal packages, including strategies and information that make such negotiations more effective for libraries. The three panelists provide their remarks below. Gale Etschmaier recounts negotiations between the Florida State University Libraries and Elsevier that led to the successful cancellation of their Elsevier "Big Deal." Robin Sinn summarizes open access efforts at the Johns Hopkins University Libraries. And, finally, Jason Priem discusses his company's product Unsub, a "data dashboard that helps libraries forecast, explore, and optimize their alternatives to the Big Deal, so they can unsubscribe with confidence."
\end{abstract}

\section{Gale S. Etschmaier on FSU Libraries Cancelling their Elsevier "Big Deal" Where we are in negotiations and mo- tivations}

Florida State University (FSU) Libraries canceled the Elsevier multi-title bundle of more than 1,800 titles, or the "big deal" in December 2018. At that time, FSU Libraries subscribed to approximately $\$ 2$ million worth of Elsevier journals as part of a statewide license agreement. The primary motivation was that the projected cost increases were not sustainable. Elsevier's pricing was based on legacy print collections and did not take into consideration changes in the Florida State institutions. The Elsevier cost increases prevented us from purchasing other critical content necessary for faculty research.

FSU Libraries had renegotiated with other vendors in the past and had broken away from at least one other vendor subscribing to the most highly used titles but not the multititle bundle.

Although we have had conversations about the need for open access publishing both within the libraries and the campus, we did not focus on principles of open access during the conversations about Elsevier. The decision to terminate the multi-title bundle has, however, opened the door to many of these conversations in a way we had not fully anticipated.

Over the course of 2018, the University Libraries, Faculty Senate Library Committee, and entire Faculty Senate discussed what action would be in the best interest of the university going forward. In March 2018, the Faculty Senate voted unanimously to support the libraries' decision to reduce Elsevier costs by subscribing to the most highly used, critical Elsevier titles.

In April, the University Libraries expressed a willingness to Elsevier to consider viable options if FSU's costs could be reduced. Negotiations throughout 2018 were unsuccessful.

\footnotetext{
Gale S. Etschmaier is dean of university libraries at Florida State University, email: getschmaier@fsu.edu, Robin N. Sinn is coordinator of the Office of Scholarly Communication at Johns Hopkins University, email: rsinn@jhu.edu, Jason Priem is cofounder of OurResearch, email: jason@ourresearch.org
}

๑ 2020 Gale S. Etschmaier, Robin N. Sinn, and Jason Priem 
By breaking away from the statewide agreement, FSU expected to spend approximately \$1 million in 2019 and subscribe to fewer journals, but continue to provide access to all previously available material through alternate sources, including tokens and document delivery.

Our library faculty had worked closely with academic departments to identify journal subscriptions within the $\$ 1$ million expenditure target that were most important to their research. The final list of 2019 subscriptions was sent to Elsevier. Throughout 2019, the library closely monitored the new service and made necessary adjustments. We encouraged faculty to contact their subject librarian if they had any difficulty accessing any journals they required, and we continued to have regular conversations about the changes.

As a result of the termination of the multi-title subscription package, we saved approximately $\$ 1$ million in that first year. We reserved $\$ 100,000$ in anticipation of copyright and document delivery fees, including direct purchase of tokens from Elsevier. As of the end of November (eight months after access to the multi-title package ended), we analyzed our expenditures and found that we had spent approximately $\$ 20,000$ for these fees.

If we had not terminated the multi-title package, we would be making across the board cuts in 2020 because of inflationary increases and a Florida legislative mandate to sequester $7 \%$ of our overall budget for emergency needs. This budget reduction is more important than ever in our current environment, and we will be looking carefully at every title we subscribe to.

We prioritized one-time purchases of resources identified as "unmet needs" by faculty with the 2019 savings. We invested in content representing narratives from the perspectives of previously marginalized communities. This supports our diversity and inclusion initiatives and enables researchers to reinterpret historical events through today's lens.

We continue to monitor and analyze article denials, ILL, and document delivery requests to identify titles that need subscriptions.
Reactions from faculty have been overwhelmingly positive. While we value the content we no longer have unlimited access to, we are able to better meet the needs of faculty and students across disciplines through careful investment in specifically identified resources.

In reflecting on our experience, communication with faculty and budget transparency were essential. We had faculty champions who partnered with us on needs analysis and solutions.

\section{Robin N. Sinn on open access efforts at the Johns Hopkins University Libraries}

The Johns Hopkins Libraries are just starting to reach out to faculty and administrators to have discussions around values and research dissemination. We have a number of faculty champions of open access, but there hasn't been a coordinated movement. Part of the reason for that is our highly decentralized organization. There is no one faculty senate--most schools have their own governance system. This decentralization extends to the libraries. The different libraries report to different administrators and receive their funding from different parts of the university.

We are making progress. In 2018, the Johns Hopkins Open Access Policy was implemented. The President's Office financially supported the development of the Public Access Submission System (PASS) to help faculty adhere to the policy. The President's Office also funded two term-limited scholarly communication librarian positions that should be rolled into the libraries permanently. Because of this support, President Ronald Daniels was invited to be a member of the National Academies of Science, Engineering, and Medicine's Roundtable on Aligning Incentives for Open Science.

With the implementation of our Open Access Policy, the Johns Hopkins Libraries have taken other steps. We updated our licensing principles and adapted the Emory Open Access Collection Development Policy to encourage our selectors to spend funds in support of open content. 
Within the Johns Hopkins Libraries, we haven't signed a transformative agreement. Because we are just starting our conversations about this with our faculty, we are still negotiating from our traditional goals of obtaining content the faculty need for research and teaching for the best price. We are following all the different options with great interest: transformative, Publish-and-Read, Read-andPublish, Subscribe to Open, and whatever comes next. Personally, I am not interested in transformative agreements with the large commercial publishers because that continues to dedicate a chunk of our collections funds to them. I'd rather spread our money out and support other ways to make research openly available. Of course, we won't make any decisions until we've learned what our faculty value. Until then, we'll get involved in some more modest efforts. For example, we participate in Annual Reviews's Subscribe to Open and support a number of open content providers like Knowledge Unlatched, arXiv, SCOAP3, and Open Library of Humanities.

We are starting to look at data and will subscribe to Unpaywall Journals (now called Unsub). The information we really want, but have to estimate, are the total author processing charges our faculty are paying to both gold OA and hybrid journals. We hope publishers will be able to provide some of that data.

It's an exciting time.

\section{Jason Priem on Unsub}

We are a small nonprofit called Our Research that got our start at a hackathon in 2012. Since then, we've built several opensource scholarly communication tools, including Impactstory and Unpaywall. Our newest tool is called Unsub (Unpaywall Journals, originally). It's a data dashboard that helps libraries forecast, explore, and optimize their alternatives to the Big Deal, so they can unsubscribe with confidence.

We launched the tool in November 2019 at the Charleston Conference (where we were awarded "most impactful new product"). Unsub works in three steps:
Step 1. Gather the data. Libraries (or consortia) upload their COUNTER reports, and we gather the rest of the needed data. For each journal, we uncover:

- citation and authorship rates from researchers at the library's institution,

- costs of different modes of access (e.g., a-la-carte subscription, ILL, or document delivery fulfillment), and

- rates of open access and backfile fulfillment.

This last category is where a lot of the value of the analysis comes from. We find that up to half of content requests can be fulfilled via open access, for free. ${ }^{1}$

Step 2. Analyze the data. We process all of this data into a customized forecasting model that predicts a given library's costs (including ILL costs) and fulfillment rates for the next five years, for each journal. Libraries can customize all the model's assumptions, reflecting different levels of risk tolerance and creating worst-case and best-case scenarios.

Step 3. Act on the data. In most cases, the models demonstrate that the Big Deal delivers great coverage, but poor value. By relying on open access, and strategically subscribing to high-value titles, libraries can often deliver around $80 \%$ of the fulfillment at $20 \%$ of the cost. $^{2}$ Armed with this data, librarians can negotiate with publishers more successfully and support decisions to cancel, should they decide to.

Approximately 300 libraries have signed up to use Unsub. Most are still in the early stages of using the tool. However, a few, like the SUNY system, are further along. SUNY have actively used Unsub to cancel their Elsevier Big Deal, replacing it with a strategically chosen bundle of high-value a-la-carte titles.

By using this bundle, SUNY will fulfill the vast majority of content requests instantly--at a much lower cost. To quote SUNY Library Senior Strategist Mark McBride: "Unpaywall Journals was instrumental in SUNY's decisionmaking process that led to us cancelling the 'big deal' with Elsevier. Their efforts resulted in us saving our campuses nearly $\$ 7$ million." 
Most libraries have reported to us that it's easy (and usually only takes a few hours) to get their Unsub account set up. One area that libraries have noted is a bit more timeconsuming is in gathering the details of titlelevel perpetual access rights. The forecasting model doesn't need this information, but it is more accurate with it, and gathering it can be a challenge. The other data sources are straightforward.

Users have overall been very supportive of our pricing model, which is to charge libraries $\$ 1,000 /$ year each (or $\$ 800 /$ year each if 10 or more sign up together, like in a consortial context). Our goal is to make the project sustainable, while also keeping it easy to afford.

\section{Post-COVID-19 environment}

As budgets are cut, Big Deals may need to be cut. But in most cases, it's not as bad as librarians or faculty fear. Open access provides a lot of headroom that didn't exist even five years ago. Librarians can limit the impact of cuts, while hitting budget goals, if they have the data they need.

I think it's a bit like the early days of "Moneyball" (true story, later a Brad Pitt movie), when baseball's Oakland A's realized that they didn't have the budget to sign the big-name stars. ${ }^{3}$ Their solution? They started bringing better data and more advanced stats into evaluating players, focusing on getting players who were good value for money rather than big names. ${ }^{4}$ And it worked. Datadriven decision-making turned the A's into a winning franchise.

A lot of libraries are about to go from New York Yankees' budgets to Oakland A's budgets. We think Unsub can help them flourish, even as they cut costs, by bringing more and better data to their decision-making.

\section{Notes}

1. Heather Piwowar, Jason Priem, Vincent Larivière, Juan Pablo Alperin, Lisa Matthias, Bree Norlander, Ashley Farley, Jevin West, and Stefanie Haustein, "The State of OA: A Large-Scale Analysis of the Prevalence and Impact of Open Access Articles," PeerJ 6 (February 13, 2018): e4375, https://doi. org/10.7717/peerj.4375.

2. "Pareto Principle," in Wikipedia, May 23, 2020, https://en.wikipedia.org/w/index. php?title=Pareto_principle $\&$ oldid $=958398047$.

3. "Moneyball," in Wikipedia, May 2, 2020, https://en.wikipedia.org/w/index.php ?title=Moneyball\&oldid=954395852.

4. "Sabermetrics," in Wikipedia, April 29, 2020, https://en.wikipedia.org/w/index. php?title=Sabermetrics\&oldid $=953918904$. n

\section{FROM ACRL PRESS}

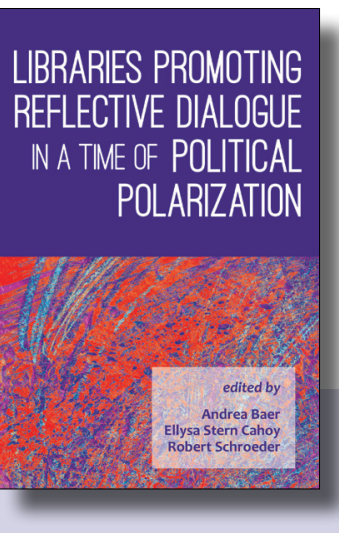
Libraries Promoting Reflective Dialogue in a Time of Political Polarization
Edited by Andrea Baer, Ellysa Stern Cahoy, and Robert Schroeder

\section{Available in the ALA Store at www.alastore.ala.org}

